competition at the 2017 AATS Annual Meeting. Deadline: January 20, 2017

Resident Poster Competition: Available for senior cardiothoracic surgery residents and/or congenital heart surgery fellows to represent their institution in a competition by presenting a scientific poster of their clinical/investigative research at the 2017 AATS Annual Meeting. Deadline: January 20, 2017

Summer Intern Scholarship: Provides first- and secondyear medical students with an eight-week summer internship in an AATS member's CT surgery department. Deadline: January 13, 2017

\section{Invest in the Future}

Every day CT surgeons transform the lives of their patients around the world. Your support is essential to ensure the future of our specialty and continue advancing global innovation in CT surgery. Please make a gift to the Foundation or renew your commitment. Together, we can promote our specialty not only for the next generation of surgeons, but also the patients they serve.

For individual and corporate/organizational giving opportunities, kindly visit the Foundation's Web site at www.aatsgrahamfoundation.org or contact the Development Office at 978-927-8330.

\title{
The Western Thoracic Surgical Association
}

\section{Applications for Membership}

The WTSA is now accepting Applications for Membership online for Active as well as Candidate membership status. Visit the WTSA Web site at www.westernthoracic.org to read the complete membership eligibility requirements and to initiate an online application.

\section{Active Member}

$\$ 375.00$ annually, plus $\$ 50.00$ initiation fee

Applicant must meet all membership criteria, including but not limited to:

- Reside within or have completed a cardiothoracic residency training program within the geographic limits of the Association.

- Have been engaged in the practice of thoracic and cardiovascular surgery for at least three years following completion of postgraduate training. If a candidate completed his/her thoracic surgical residency or a oneyear clinical fellowship in an institution within the geographic limits of the Association, such completion may count toward one of the three years of practice.

- Have a full and unrestricted license to practice medicine in his or her respective state or province, and have a current appointment on the surgical staff of a hospital with no reportable action pending which could adversely affect such applicant's staff privileges at any hospital.

\section{Candidate Member}

$\$ 100.00$ annually

Applicant must meet all membership criteria, including but not limited to:

- Be matched or enrolled in either a cardiothoracic surgery education program accredited by the Residency Review Committee for Thoracic Surgery under the authority of the ACGME or a program approved for cardiothoracic surgery education by the Royal College of Surgeons of Canada — or their equivalency - from within the Association's geographic limits. Individuals who have completed their education in one of the above programs but do not yet meet all of the criteria for Active membership also are eligible to apply for Candidate membership. Individuals who trained outside the Association's geographic limits who are now residing within the Association's boundaries but do not yet have three years in practice may also apply for Candidate membership.

An application must include the following uploads: a photo, a complete curriculum vitae with bibliography, and, for Active applicants, the 3 most significant articles that s/he personally wrote. The application must be completed and submitted online by March 1, 2017, and all support letter(s) (three for Active applicants, one for Candidates) uploaded by that applicant's sponsor(s) by March 31, 2017, in order for the applicant to be considered for election to membership at the 2017 Annual Meeting.

\section{WTSA 43rd Annual Meeting}

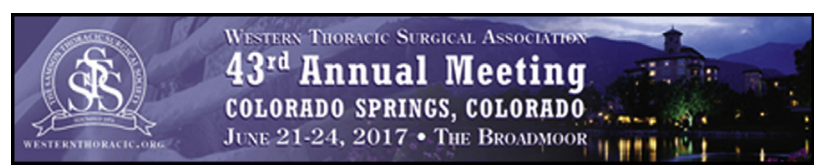

Save the Date!

June 21-24, 2017

The Broadmoor

Colorado Springs, Colorado 